Felix Wilhelm Siebert, Michael Oehl, Florian Bersch, Hans-Rüdiger Pfister

\title{
The exact determination of subjective risk and comfort thresholds in car following
}

Journal article | Accepted manuscript (Postprint)

This version is available at http://dx.doi.org/10.14279/depositonce-8785

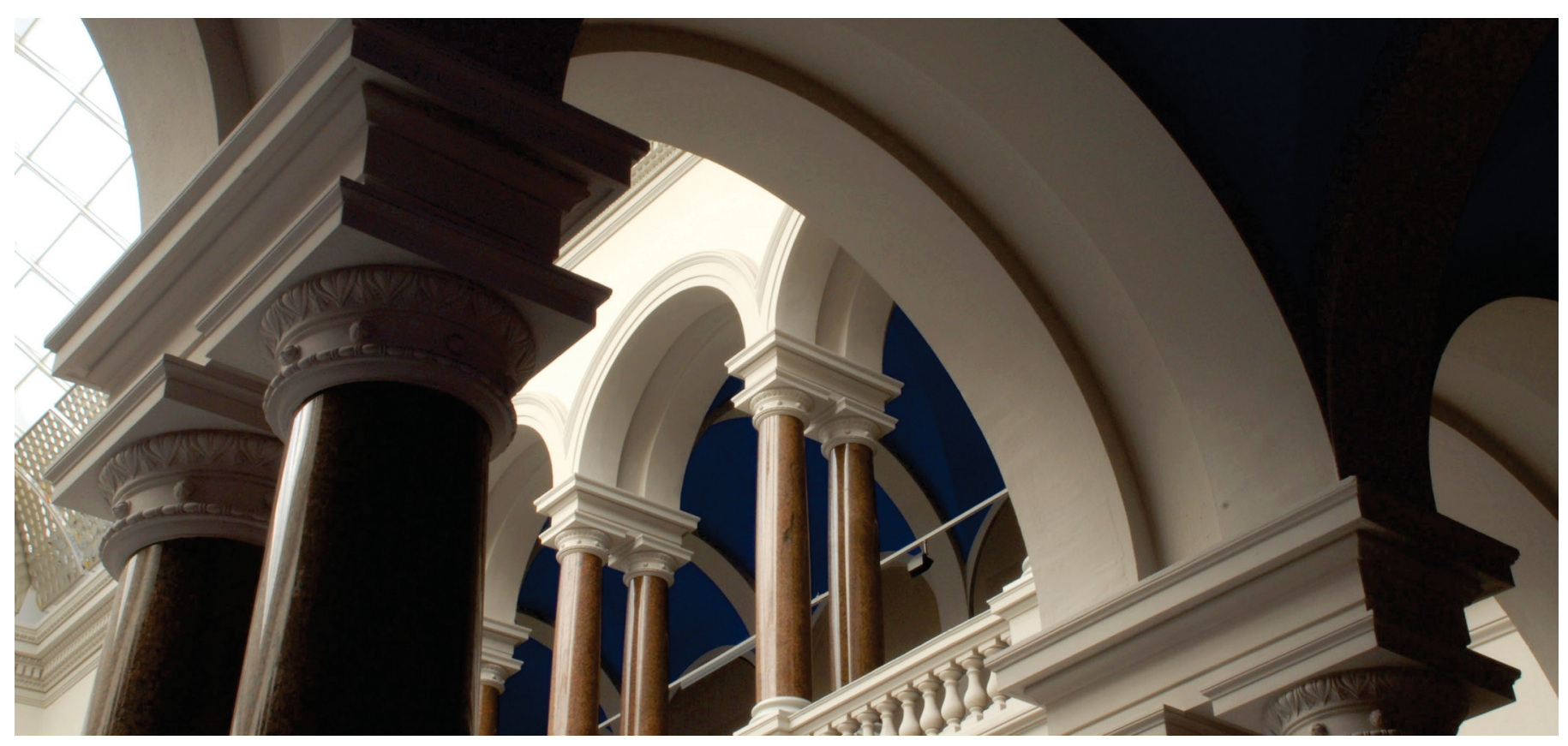

Siebert, F. W., Oehl, M., Bersch, F., Pfister, H.-R. (2017). The exact determination of subjective risk and comfort thresholds in car following. Transportation Research Part F: Traffic Psychology and Behaviour, 46, 1-13. https://doi.org/10.1016/j.trf.2017.01.001 
This is the Accepted Manuscript of the following article published by Elsevier in Transportation research part F: traffic psychology and behaviour [4. February 2017]:

Siebert, F. W., Oehl, M., Bersch, F., \& Pfister, H. R. (2017). The exact determination of subjective risk and comfort thresholds in car following. Transportation research part F: traffic psychology and behaviour, 46, 1-13. https://doi.org/10.1016/j.trf.2017.01.001

This manuscript is not the copy of record and may not exactly replicate the final, authoritative version of the article.

This work is licensed under a Creative Commons Attribution-NonCommercial-NoDerivatives 4.0 International License, http://creativecommons.org/licenses/by-nc-nd/4.0/. 
The exact determination of subjective risk and comfort thresholds in car following

Felix Wilhelm Siebert ${ }^{\mathrm{a}}$, Michael Oehl ${ }^{\mathrm{b}}$, Florian Bersch ${ }^{\mathrm{b}}$, Hans-Rüdiger Pfister $^{\mathrm{b}}$

Corresponding Author: Felix Wilhelm Siebert

${ }^{\mathrm{a} C h a i r}$ of Human-Machine Systems

Mechanical Engineering and Transport Systems

Department of Psychology and Ergonomics

Marchstraße 23

10587 Berlin

Germany

${ }^{\mathrm{b}}$ Institute of Experimental Industrial Psychology

Leuphana University of Lueneburg

Wilschenbrucher Weg 84a

21335 Lüneburg

Germany

E-mail: felix.siebert@ tu-berlin.de

E-mail: oehl@uni.leuphana.de

E-mail: bersch@stud.leuphana.de

E-mail: pfister@uni.leuphana.de 


\begin{abstract}
In this study the location of vehicle to vehicle distance thresholds for self-reported subjective risk and comfort was researched. Participants were presented with ascending and descending time headway sequences in a driving simulator. This so called method of limits of ascending and descending stimuli (Gouy, Diels, Reed, Stevens, \& Burnett, 2012) was refined to efficiently determine individual thresholds for stable time headways with a granularity of 0.1 seconds. Time headway thresholds were researched for 50,100 , and $150 \mathrm{~km} / \mathrm{h}$ in a city, rural, and highway setting. Furthermore, thresholds for self-driving (level 0 automation: NHTSA, 2013) were compared with thresholds for the experience of subjective risk and comfort in assisted driving, similar to adaptive cruise control (level 1 automation). Results show that preferred individual time headways vary between subjects. Within subjects however, time headway thresholds do not significantly differ for different speeds. Furthermore we found that there was no significant difference between time headways of self-driving and distanceassisted driving. The relevance of these findings for the development of adaptive cruise control systems, autonomous driving and driver behavior modelling is discussed.
\end{abstract}

\title{
Keywords
}

Time Headway; Method of Limits; Driver Behaviour Modeling; Risk; Comfort 


\section{Introduction}

Recent studies suggest that the relation between time headway in car following and the subjective experience of a driver is subject to a threshold effect (Lewis-Evans, De Waard, \& Brookhuis, 2010; Siebert, Oehl, \& Pfister, 2014). This means that drivers do not experience subjective risk for time headways higher than a specific threshold, while the subjective risk increases significantly for time headways lower than the specific subjective threshold. Studies have also found a consistency of time headway thresholds over different speeds (Siebert et al., 2014). These findings of a threshold effect for time headway and its consistency over different speeds are relevant for the advancement of theoretical issues in traffic psychology, i.e., driver behavior modelling, as well as applied issues such as adaptive cruise control and autonomous driving.

In driver behavior modelling there is a theoretical dispute that can be best observed between so called "zero risk" models (Näätänen \& Summala, 1974; Summala, 1988) and "target risk" / “target task difficulty” models (Fuller, 2005; Taylor, 1964). In zero risk models it is generally assumed that drivers choose their path and speed in a way that minimizes their experience of risk. In these models drivers will change the path or speed of their vehicle as soon as any feeling of risk arises no matter how small. Following the "target risk" or "target task difficulty" models however, drivers do not choose their path and speed to completely avoid a feeling of risk or task difficulty. In these "target" models, drivers aim for a target level of risk or task difficulty that is higher than zero. If the driving situation leads to a subjective risk level or a task difficulty that is below the target level, a driver will change the speed and/or path of his vehicle to increase his subjective feeling of risk or perceived task difficulty until the target risk / task difficulty level is reached and vice versa. For the "target" models to be applicable to driving there has to be a level of variance in drivers' subjective experience of risk or task difficulty in normal driving situations. Target models do not imply that drivers actively drive in a reckless way where they expect an accident, i.e. that the accident risk is higher than zero, but that their experienced level of general risk / task difficulty is higher than zero. Following the "zero risk" models there should be very little variance in the subjective feeling of risk, because following this theory, drivers will avoid risky situations thereby maintaining a constantly low level of subjective risk.

The findings of a threshold effect for the influence of time headway on the subjective experience of risk (Lewis-Evans et al., 2010; Siebert et al., 2014) give credence to zero risk models. If a driver does not experience subjective risk up until an individual threshold, there 
is no variance in subjective risk experience before the threshold. Therefore, a driver cannot use subjective risk to select a time headway respectively distance to another vehicle that he likes to keep. The threshold effect further presumes a significant increase in subjective risk for time headways lower than the individual threshold. In theory, the target level of risk could be located in this area. This, however, is unlikely for two reasons; the sharp increase in the subjective risk experience would either lead to a very large target level of risk, or would require very frequent and precise control of time headway. Furthermore it was shown by Siebert et al. (2014) that drivers experience time headways lower than the threshold as unpleasant, making it unlikely that drivers would choose a time headway that is lower than the subjective threshold.

Consequentially the existence of a threshold effect and the resulting assumption of the validity of the zero risk models can lead to the dichotomization of the subjective risk experience of drivers. A researcher therefore does not need to ask "how much risk is experienced?" but is allowed to ask "is risk experienced or not?".

Apart from a general threshold effect, there is evidence for a consistency of individual time headways over different speed conditions (Ayres, Li, Schleuning, \& Young, 2001; Siebert et al., 2014; Taieb-Maimon \& Shinar, 2001; Winsum \& Heino, 1996). This study aims to replicate these findings of constant individual time headways over different driving speeds for a broader speed range with an efficient and precise method that can alleviate some confounding interference of existing study designs.

Besides theoretical issues, the existence of a threshold effect of time headway on the subjective experience of a driver is meaningful to applied issues as well. As discussed earlier, drivers will change their path or speed once they experience subjective risk when they drive themselves. With the adoption of advanced driver assistance systems, such as adaptive cruise control (level 1 automation), and the emergence of level 3 automation in vehicles (NHTSA, 2013) the task of changing the vehicle's speed and its resulting distance to other road users is carried out by the vehicle itself. In level 1 automation, drivers might decide not to use a system that does not adhere to subjective time headway thresholds. In level 3 automation systems the problem of not-individually adjusted time headway can be much more dangerous. Level 3 automation allows the driver to be distracted from the driving task and just requires occasional control. This might lead to situations in which a driver refocuses on the driving task after being distracted, perceiving the car to car distance as risky, and taking over control of the car in a hasty and dangerous way. Furthermore, perceiving a level 3 automation system 
as risky, can lead to a decline in trust in the system and general disuse of the system (Parasuraman \& Riley, 1997). Taking into account the subjective experience of the driver will therefore be a prerequisite for the adoption and frequent usage of automation systems of different levels. This will be especially important in the initial usage phase, where users have not adjusted the system for their subjective preference.

Accurately identifying the location of the time headway threshold for an experience of subjective risk could therefore help to design the automation to stay above said threshold. This higher than personal threshold headway can help to build trust and prevent a feeling of subjective risk in the driver, thereby increasing the use of such systems (Muir, 1994; Pereira, Beggiato, \& Petzoldt, 2015), preventing dangerous takeover situations by the driver, and lowering the number of traffic accidents.

In the location of the time headway threshold rests another important research question for the application of advanced driver assistant systems. What is the relation between time headways of drivers when they have full control of the car (level 0 automation), compared to time headway thresholds in automated driving (level 1 automation and higher)? An earlier study by Lewis-Evans et al. (2010) suggests that time headways of self-driving are congruent with time headway thresholds of subjective risk experience in driving with adaptive cruise control (level 1 automation). This study aims to replicate these findings of a high correlation of time headways in self-driving and driving with an adaptive cruise control.

Apart from subjective risk, which helps to locate the absolute boundaries of what is an acceptable distance in car following, it is also import to locate the range of distances that drivers feel comfortable to keep (Marsden, McDonald, \& Brackstone, 2001; Stanton \& Young, 2005), as comfortable time headways might differ from non-risky thresholds. In earlier studies, subjective risk and comfort experience were investigated together in a within subject design and risk and comfort ratings showed a significant and high correlation (Lewis-Evans et al., 2010; Siebert et al., 2014). While Lewis-Evans et al. (2010) argue that the correlation of different subjective variables might be a sign for an underlying construct that is rated, they also support an effort to try and separate subjective variables. We therefore used a betweensubject design for the two subjective variables. This can also help to counter a possible response bias, stemming from the presentation of the two subjective variables together. For theoretical as well as applied issues, it is of further interest to identify the threshold location as precisely as possible. The studies on time headway thresholds by Siebert et al. (2014) and Lewis-Evans et al. (2010) were designed to research a broad range of time 
headways ( 0.5 to 4.0 seconds), but had a very low spatial resolution of only 0.5 seconds time headway. This study utilizes a finer resolution of the time headway variable by using an enhanced type of the psychophysics method of limits. The basic principle of this method is to present a participant with ascending and descending sequences of stimuli to locate a stimuli specific threshold. The details of this method are explained in the methods section. The precise knowledge of individual time headway thresholds in level 1 automation due to the use of our method, allows us to compare this threshold to self-driving thresholds, which can be measured as precise.

\section{Aims of this Study}

In the simulator study by Lewis-Evans et al. (2010) participants were presented with eight different time headways ranging from 0.5 to 4.0 seconds divided in 0.5 second time headway steps at a speed of $50 \mathrm{~km} / \mathrm{h}$. The different time headways were each presented for approximately 180 seconds in a random order. Participants had control over the steering wheel, while the distance to another car was controlled by the simulator, resulting in the different time headways. For every time headway, participants rated their subjective risk, task difficulty, effort, and comfort on a 7-point Likert scale. The study by Siebert et al. (2014) had a similar design with two added speed conditions of 100 and $150 \mathrm{~km} / \mathrm{h}$. The duration of each time headway condition was shortened to 60 seconds. The division of the time headway space in 0.5 second increments in both of the studies might have suppressed some of the variance in subjective ratings, since even a seemingly small time headway change of 0.5 seconds is equivalent to a change in the vehicle to vehicle distance of $6.9 \mathrm{~m}(50 \mathrm{~km} / \mathrm{h}), 13.9 \mathrm{~m}(100$ $\mathrm{km} / \mathrm{h})$, or $20.8 \mathrm{~m}(150 \mathrm{~km} / \mathrm{h})$ respectively.

While our current study investigates the same time headway range ( 0.5 to 4.0 seconds) as the preceding studies, the variation of the time headway variable was modified. This resulted in a higher resolving power of 0.1 time headway seconds compared to 0.5 time headway seconds of earlier studies. The spatial resolution of this refined design is equivalent to a finely graduated vehicle to vehicle distance of $1.39 \mathrm{~m}$ for $50 \mathrm{~km} / \mathrm{h}, 2.78 \mathrm{~m}$ for $100 \mathrm{~km} / \mathrm{h}$, and $4.17 \mathrm{~m}$ for $150 \mathrm{~km} / \mathrm{h}$. Furthermore, to be able to locate the individual time headway threshold of a participant more efficiently, the so called "method of limits" was used (Brecher, 1934; Fechner, 1860; Fletcher \& Wegel, 1922; Gouy, Diels, Reed, Stevens, \& Burnett, 2012, 2013). This was done since the randomized presentation of time headways in the range of 0.5 to 4.0 seconds with a resolution of 0.1 seconds would have resulted in 36 different time headway 
situations for every speed condition. The method of limits provided us with a tool to more efficiently pinpoint a participant's individual time headway threshold with a fine resolution of 0.1 seconds. This time headway threshold position was used as the dependent variable in our study.

The method of limits belongs to the methods developed in the field of psychophysics founded by Gustav Theodor Fechner (1860). Psychophysics link physical quantities, e.g., intensity of light or weight, to the subjective experiences produced by these quantities in humans, e.g., perceived brightness or heaviness. The method of limits was designed to locate absolute sensory thresholds. It was used by Fletcher and Wegel (1922) and further developed by Gerhard Brecher (1934) to locate sensory thresholds of audio signals. In his study Brecher played a sequence of sounds of different frequencies to participants, starting with either a very low or a very high frequency. When starting with a low frequency, the frequency increased until participants reported that they heard something, i.e., had a hearing sensation. When starting with a high frequency, the frequency was decreased until participants reported that they did not hear a sound anymore, i.e., that there was no hearing sensation anymore. Each increasing or decreasing frequency sequence was repeated five times and the points of transition from hearing to non-hearing (sensation to no sensation) or non-hearing to hearing (no sensation to sensation) were noted. So called "transition points" were then calculated by taking the average of the two physical stimuli that represented sensation and no sensation in a sequence, and vice versa. The transition point for a decreasing sequence therefore lies in the middle of two frequency points that were presented, i.e., the frequency where a participant still heard a tone and the frequency where a participant did not hear a tone anymore. The reasoning behind this is that since a researcher cannot exactly pinpoint were the shift from sensation to no sensation occurred, the mean between the two stimuli is used. While this recalculation of transition points does not influence the resulting average that is the threshold, it is important for the understanding of sole transition points (Gescheider, 1997). Brecher then calculated the mean of the frequency of the 10 transition points as a hearing threshold for the frequency of audio signals.

Analog to Brecher's sequences of increasing and decreasing frequencies, we programmed sets of ascending and descending time headway sequences in the driving simulator called "fixed follow" conditions. Using a time headway range of 0.5 to 4.0 seconds, an ascending sequence started with a fixed time headway distance of 0.5 seconds to another car. After 20 seconds the car driving ahead accelerated for one second leading to an increase in time headway of 0.5 seconds and so resulting in a new time headway of 1.0 seconds. Time headway increased in 
0.5 second steps up to the maximum time headway of 4.0 seconds. In the descending sequence, participants were presented with a time headway of 4.0 seconds that decreased in 0.5 second steps to the minimum time headway of 0.5 second (top of Figure 1). The time headways were fixed, since participants could not use the gas or brake pedal to influence their speed and therefore all presented time headways could not be changed. The time headway change of 0.5 seconds, either in ascending or descending order, was labelled a "large scale sequence", because, as explained earlier, it represents a large change in the vehicle to vehicle distance. The order of ascending and descending large scale sequences are presented at the top of Figure 1.

Large scale sequences:

Time headway (s)

\begin{tabular}{|c|c|c|c|c|c|c|c|c|c|}
\hline & 0.5 & 1.0 & 1.5 & 2.0 & 2.5 & 3.0 & 3.5 & 4.0 & \\
\hline \multirow[t]{2}{*}{ Ascending } & & & $\rightarrow$ & $x_{1}$ & & & & & \\
\hline & & & & & $\mathrm{y}_{1}$ & $\leftarrow$ & & & Descending \\
\hline
\end{tabular}

Small scale ascending sequences:

Time headway (s)

\begin{tabular}{|c|c|c|c|c|c|c|}
\cline { 2 - 7 } \multicolumn{1}{c|}{} & $\mathrm{x}_{1}-0.5$ & $\mathrm{x}_{1}-0.4$ & $\mathrm{x}_{1}-0.3$ & $\mathrm{x}_{1}-0.2$ & $\mathrm{x}_{1}-0.1$ & $\mathrm{x}_{1}$ \\
\hline Ascending & & & $\rightarrow$ & $\mathrm{x}_{2}$ & & \\
\cline { 2 - 7 } & & & & & \\
\hline
\end{tabular}

Small scale descending sequences:

Time headway (s)

\begin{tabular}{|c|c|c|c|c|c|l|}
\hline $\mathrm{y}_{1}$ & $\mathrm{y}_{1}+0.1$ & $\mathrm{y}_{1}+0.2$ & $\mathrm{y}_{1}+0.3$ & $\mathrm{y}_{1}+0.4$ & $\mathrm{y}_{1}+0.5$ & \\
\hline & & $\mathrm{y}_{2}$ & $\leftarrow$ & & & Descending \\
\hline
\end{tabular}

Figure 1. Experimental design of large and small scale time headway sequences. A participant's report of a transition is labelled as $\mathrm{x}_{\mathrm{i}}$ for ascending sequences and $\mathrm{y}_{\mathrm{i}}$ for descending sequences.

The experimental design of ascending and descending time headway sequences is similar to two studies by Gouy et al. $(2012,2013)$, who varied time headway between 0.1 and 2.5 second, using ascending and descending 0.1 second steps. Each time headway step was presented for 5 seconds. The speed of the lead vehicle and the participants' car was fixed at approximately $110 \mathrm{~km} / \mathrm{h}$ and not varied. Participants did not have control over the steering wheel during ascending and descending time headways.

To research if comfort thresholds differ from risk thresholds, participants were randomly assigned to either a "comfort" or a "risk" group. Participants in the comfort group were instructed to monitor their subjective comfort in the driving situation with a special focus to the vehicle to vehicle distance. Participants were further instructed to immediately report a change in their comfort experience, i.e., when their experience of the vehicle to vehicle distance changed from comfort to discomfort or from discomfort to comfort in the fixed 
follow conditions, by addressing the experimenter. Participants were instructed to use the word "now" ("Jetzt" in German) to indicate this point, although this was not enforced and participants sometimes used different words to indicate that a threshold was reached.

Participants assigned to the risk group were instructed to monitor their subjective experience of risk, also with a focus on the vehicle to vehicle distance. As in the comfort group, participants in the risk group were instructed to report changes in their subjective experience of risk, i.e., when their experience of the vehicle to vehicle distance changed from risky to not risky or the other way around in the fixed follow conditions, by saying "now" ("Jetzt").

Since participants only reported a change in their subjective risk or comfort experience, the risk and comfort reports are binary, i.e. participants in the risk group are either reporting risk or no risk, while participants in the comfort group report comfort or a lack of comfort. Assignment to either comfort or risk group was used as a between-subject independent variable in this study.

The report of a change of a participant's subjective risk or comfort allows us to assess the subjective experience of said participant. It is important to distinguish this self-report of a participant's subjective experience from the direct observance of risk or comfort, or any form of specific crash risk. Strictly speaking, we do not measure risk or comfort, but we measure reported risk and reported comfort.

To be able to locate time headway thresholds on a scale of 0.1 time headway seconds, each "large scale sequence" was followed by a "small scale sequence". The small scale sequence presented time headways in 0.1 second increments starting with the time headway of the large sequence that was presented before a participant reported a change in his subjective experience (see Figure 1). As in the large scale sequences, time headways were fixed and could not be influenced.

Analogue to the study by Lewis-Evans et al. (2010), a free follow condition was programmed to allow participants to set their preferred time headway by themselves by adjusting their speed. Adhering to the design of the fixed follow conditions, there were ascending and descending free follow conditions. In ascending free follow conditions, the scenario started with a vehicle to vehicle distance of 0.5 seconds time headway. Participants then increased the distance by decelerating their vehicle until they felt comfortable respectively did not experience risk anymore. In the descending free follow conditions the scenario started with a time headway of 4.0 seconds. Participants then decreased the distance until they did not feel comfortable anymore respectively experienced risk. The average of the two time headways of 
ascending and descending free follow conditions was calculated as the free follow time headway threshold. The type of control over the vehicle, labelled free follow or fixed follow condition, was used as a within-subject independent variable in this study.

To investigate the influence of speed on time headway thresholds, fixed and free follow conditions were presented at 50,100 , and $150 \mathrm{~km} / \mathrm{h}$.

In this study the influence of the independent variables speed, control, and type of subjective experience on time headway thresholds of drivers was researched. Speed was varied threefold within subjects $(50,100,150 \mathrm{~km} / \mathrm{h}$ ), control was varied two-fold within subjects (free follow, fixed follow), and subjective experience was varied two-fold between subjects (risk group, comfort group).

\subsection{Hypotheses}

Based on the results from Lewis-Evans et al. (2010) and Siebert et al. (2014), we expected the mean time headway threshold for the subjective experience of risk and comfort to be located between 1.5 and 2.0 seconds.

Adding to this, we expected that the thresholds would be constant over different speed conditions, i.e., that different speeds do not significantly influence the threshold locations as in the study by Siebert et al. (2014).

We further expected a high positive correlation between individual time headway thresholds of 50 and $100 \mathrm{~km} / \mathrm{h}, 100$ and $150 \mathrm{~km} / \mathrm{h}$, and 50 and $150 \mathrm{~km} / \mathrm{h}$, indicating a stability of individual time headway thresholds over different speeds.

Furthermore, we hypothesized that the threshold for the experience of comfort would be higher than the threshold for the experience of risk, i.e., that the comfort group would report a loss of a subjective feeling of comfort at a higher time headway than the risk group would report a subjective experience of risk.

We additionally hypothesized that individual time headway thresholds of fixed and free follow conditions would correlate positively significantly, i.e., if a participant's individual threshold in fixed follow driving is relatively small, it will also be relatively small in free follow driving. 


\section{Method}

\subsection{Participants}

38 participants were recruited at the Leuphana University Lüneburg as a convenience sample. All recruited participants completed the experiment. 20 participants were female and 18 participants were male. As the only prerequisite, participants had to be in possession of a valid driver's license. Participants had a mean age of $M=24.11$ years $(S D=4.6)$ and held their driver's license on average for $M=6.59(S D=4.41)$ years. Participants estimated that they drove $M=4142.24(S D=6966.08)$ kilometers per year on average. 11 participants owned a car, while 27 did not own a car. Students were awarded with test-subject hours for the duration of the experiment, which need to be collected during students' years of study. 20 participants were assigned to the comfort group (10 female, 10 male), 18 participants were assigned to the risk group (10 female, 8 male). After the experiment was conducted, participants were told about the purpose of the experiment and could leave their e-mail address to get informed about the results of the study.

\subsection{Materials}

The experiment was conducted in the fixed base driving simulator at the Institute of Experimental Industrial Psychology at the Leuphana University Lüneburg. The driving simulator cabin was taken from a Volkswagen Golf 4 GTI, a medium class vehicle. The steering wheel (taken from a Golf 4 non-GTI model) was connected to the base of a Logitech G25 Racing wheel. The pedals used in the study were generic gaming pedals from Logitech. The simulator cabin was taken from a car with automatic transmission, therefore the simulated car had an automatic gearbox. To simulate the driving environment, the SCANeR Studio driving simulation software version 1.3 from Oktal was used. The driving environment was projected on to three screens in front of the driving cabin, each screen had a size of $1.4 \mathrm{x}$ $1.4 \mathrm{~m}$. The outer screens were positioned in an angle of $120^{\circ}$ to the center screen. The driver seat was positioned $2 \mathrm{~m}$ from the center screen, resulting in a horizontal field of view of approximately $110^{\circ}$ and a vertical field of view of approximately $30^{\circ}$. The physical eye height of the participants was approximately $1.25 \mathrm{~m}$ (with a small influence of the height adjustment of the driver seat). The simulated eye height was fixed at $1.25 \mathrm{~m}$. The simulated car model was a Citroën C4. The simulator is pictured in Figure 2. To shut out ambient sounds and light, curtains surrounded the cabin and the projection screens. The test supervisor sat behind the cabin in the corner of the simulator room, controlling the simulation from outside of the 
participant's field of view. Simulation sounds (engine and wind) were produced from two speakers in front of the cabin. Simulation data was saved to a plain text file with the help of a python script with a frequency of $20 \mathrm{~Hz}$. The speedometer of the cabin was turned off for the whole experiment. This was done to not distract participants, since they were asked to focus on the distance to the leading vehicle for the whole sequence of 20 seconds.

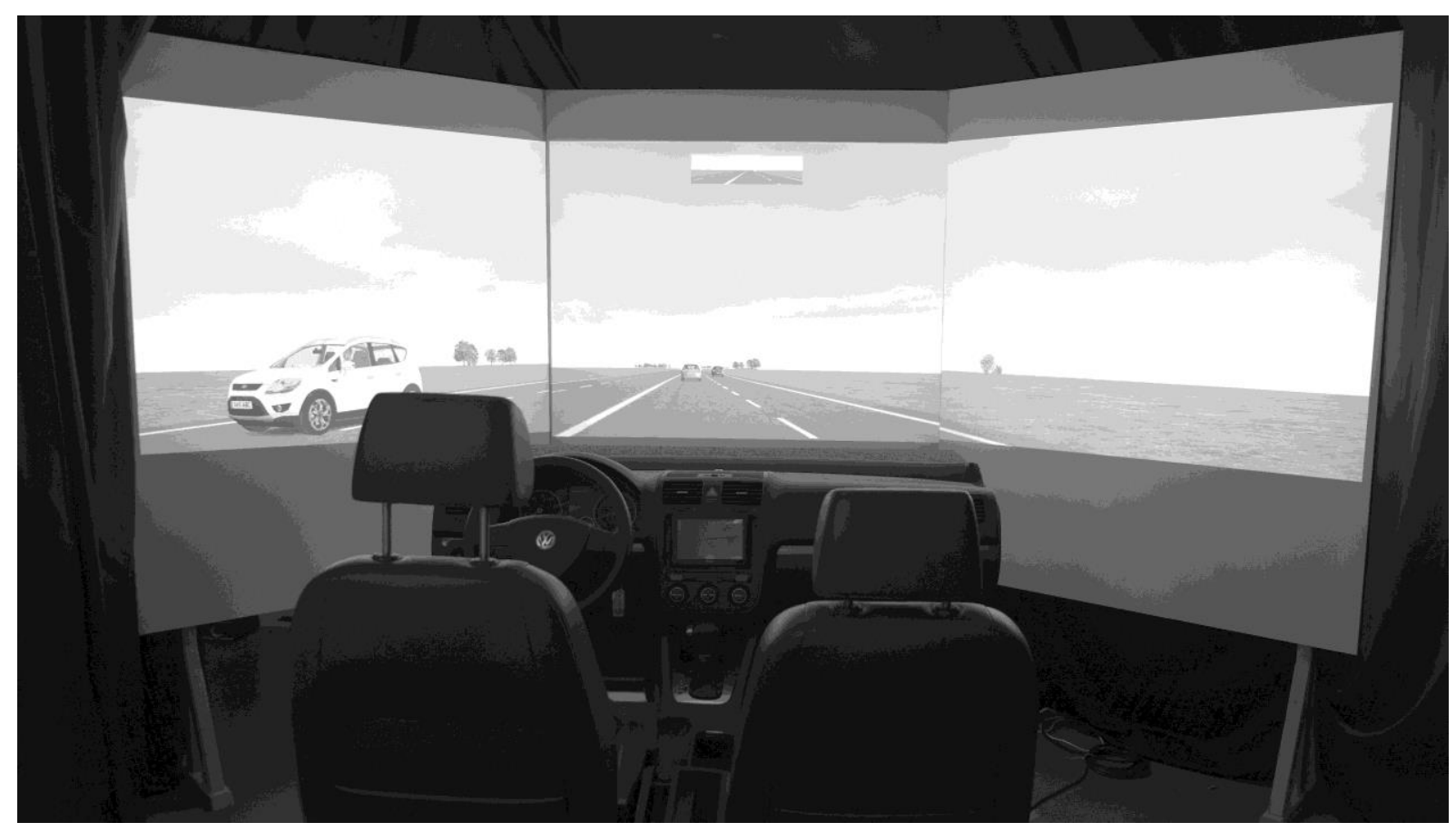

Figure 2. Fixed base driving simulator and simulated driving environment of the $100 \mathrm{~km} / \mathrm{h}$ condition.

The simulated driving environments were modelled after a generic German city road, a rural road, and a highway. The city road environment consisted of two lanes with one lane reserved for oncoming traffic. The two lanes were divided by a dashed line. Each lane of the city road was $3 \mathrm{~m}$ wide, and the road was modelled after the "Regelquerschnitt 9,5" or RQ9,5, which is a standard of road construction in Germany. The roadside consisted of an adjacent sidewalk and generic inner city buildings. The rural road had four lanes, two in each direction with a solid line separating traffic of different directions and a dashed line separating lanes for same direction traffic. Each lane of the rural road was $3.25 \mathrm{~m}$ wide, and modelled after the German road construction standard RQ20. The rural road environment had randomly placed trees and rural buildings on the side of the road. The highway environment was modelled after the German road construction standard RQ33, and consisted of six lanes with three lanes in each direction. There was a central barrier dividing traffic of different directions, and dashed lane markings dividing traffic lanes of the same direction. Each lane was $3.5 \mathrm{~m}$ wide. There were 
randomly placed trees next to the highway. In all driving environments there was only minimal curvature and no slope. Objects in all three traffic environments, i.e., buildings and trees, were placed with a minimal distance of $20 \mathrm{~m}$ to the traffic lanes. There were gentle curves in every traffic environment and there was no cross traffic or pedestrians. All simulated vehicles adhered to traffic rules, did not overtake and drove 1-5\% slower than the participants' car and the leading vehicle. Distances between simulated vehicles, other than the participant's and the lead vehicle, were programmed as a minimum of two seconds, to prevent a carryover effect from observed time headways in traffic to the time headway of participants (Gouy, Wiedemann, Stevens, Brunett, \& Reed, 2014).

Ascending and descending fixed follow large scale and small scale scenarios as well as ascending and descending free follow scenarios for all three different speeds were preprogrammed. Every time headway step, small scale or large scale lasted 20 seconds, while each change in time headway lasted one second. The order of the scenarios was randomized for every participant with the help of the built in script of the SCANeR software as well as external python scripting.

The choice of a driving simulator as a research tool leads to the question of the generalizability of the data acquired in this study. It has to be stated that every driving simulator system is different, using a unique combination of simulation software, vehicle hardware, and projection size. With this caveat in mind, the validity of a driving simulator is broadly characterized by two types of validity: absolute / physical validity, which describes the accuracy with which the physical properties of real life driving are presented in the simulation; and relative / behavioral validity, which is given when different experimental conditions lead to the same behavioral changes of a driver when comparing real life and simulated driving (Godley, Triggs, \& Fildes, 2002; Yan, Abdel-Aty, Radwan, Wang, \& Chilakapati, 2008).

While we did not assess the absolute validity of our simulation, we used a projection with a large field of view and chose a natural eye-height of the participant. A large field of view allows for good speed perception, while a natural simulated and physical eye-height can prevent misjudgment of distances in simulators (Kemeny, \& Panerai, 2003). Results of a study by Purucker, Rüger, Schneider, Neukum, and Färber (2014) suggest that longitudinal distances between vehicles are perceived as more critical in simulated than in real-life driving. This effect could help to explain discrepancies between the relatively large time headways found in simulator studies (Lewis-Evans et al., 2010; Siebert et al., 2014) and relatively small 
time headways found in car following in real-life driving (Brackstone, Sultan, \& McDonald, 2002, Brackstone, Waterson, \& McDonald, 2009). Therefore, results from our driving simulator may not have absolute validity, i.e. time headway thresholds from this study might not be directly translatable to time headway thresholds in real life driving.

For relative validity of results on vehicle to vehicle distance in simulators, not many results can be found. Yan et al. (2008) found that results on following distance on approach to intersections show the same effects in real life and simulated driving. Risto and Martens (2014) found differing time headways dependent on instructions and reproduced this effect in a driving simulator. This indicates relative validity of driving simulators for time headway perception.

Results from studies on relative validity of other driving variables, such as speed and lateral control of the vehicle indicate a relative validity of driving simulators (Bella, 2008; Carsten, \& Jamson, 2011).

\subsection{Procedure}

After filling out a demographic questionnaire and receiving their group specific instruction, participants were presented with a training session in the driving simulator that consisted of two parts. In the first part of training, participants familiarized themselves with the control of the simulator by driving on an inner city, a rural, and a highway road. The roads were similar to the roads used later in the experiment described in the "materials" section. The second part of the training session consisted of a descending and an ascending time headway sequence presented at the speed of $100 \mathrm{~km} / \mathrm{h}$. Participants were instructed to report a change in their experience of comfort respectively risk with regard to the vehicle to vehicle distance. There was no other traffic apart from the participants' and the leading vehicle in the training sessions. Since the wording of the instruction for reporting a change in subjective experience can have an influence on participants' reports, it is quoted in full in German and then translated into English. The text in square brackets contains instructions for the researcher.

"Vor dir fährt ein anderes Auto und der Abstand zu diesem Auto wird sich schrittweise verändern. Der Abstand ist zu Beginn entweder sehr klein und wird dann größer, oder er ist sehr groß und wird dann kleiner. Beurteile nur den Abstand und nicht das Abbremsen oder Beschleunigen des Fahrzeugs. Hast du hierzu fragen? [Falls 
Fragen, noch mal erklären] In dieser Situation wird der Abstand sehr groß sein. Sag mit bitte Bescheid, sobald du den Abstand als risikoreich empfindest. [Warten auf Rückmeldung von Proband, aufsteigende Bedingung laden wenn keine Fragen] In dieser Situation wird der Abstand zu Beginn sehr klein sein. Sag mir bitte Bescheid sobald du den Abstand nicht mehr als risikoreich empfindest.“

\section{In English:}

"There is a car in front of you, and the distance to this car will change in steps. In the beginning the distance is either very small and gets bigger, or is very big and gets smaller. Please only judge the distance and not the deceleration or acceleration of the vehicle. Do you have any questions? [If there are questions, explain again] In this situation the distance will be very big. Please tell me when you perceive the distance as risky. [Wait for report from participant, load ascending condition if there are no questions] In this situation the distance will be very small in the beginning. Please tell me when you perceive the distance as not risky anymore."

This initial instruction for the risk group is from the training session. For the comfort group two sentences were changed, the sentence "Please tell me when you perceive the distance as risky." was changed to "Please tell me when you perceive the distance as not comfortable anymore", the sentence "Please tell me when you perceive the distance as not risky anymore" was changed to "Please tell me when you perceive the distance as comfortable".

The same instruction was repeated for the small scale sequences in the training. The instruction was repeated again before the main part of the experiment, where a sentence about other cars on adjacent lanes was added, informing participants that other traffic would stay on their respective lanes. Participants were not informed how to interpret "risk" or "comfort", i.e. risk and comfort were not defined for the participants.

When participants indicated that they felt capable driving the simulator and that they understood the task of reporting a change in their subjective risk respectively comfort experience, the main part of the experiment was started. 
In the main part of the experiment, participants were first presented with the fixed follow conditions, i.e., with the ascending and descending time headway sequences of all three speeds in a randomized order. The first sequence, ascending or descending, was always a large scale sequence with a change of time headway in 0.5 second increments. This large scale sequence was then always followed by a fine graduated small scale sequence of the same speed and direction (ascending or descending). The small scale sequence started at the time headway step of the large scale sequence that was presented to the participant before he or she reported a transition (Figure 1). The procedure in the small scale sequences was the same as in the large scale sequences. When participants reported a change in their experience of risk respectively comfort, the sequence was stopped and the experimenter wrote down the condition time at which a participant reported a transition in his or her subjective experience. This was done to be able to later extract the time headway distance at the transition point from the simulator data.

After the presentation of the 12 fixed follow sequences, participants were presented with the 6 free follow sequences. As explained earlier, free follow conditions were also presented as ascending and descending conditions, i.e., conditions started with a large time headway distance of 4.0 seconds or a small time headway distance of 0.5 seconds to another vehicle. In contrast to the fixed follow conditions, participants had full control of the car in the free follow conditions. In descending free follow sequences, starting with a time headway of 4.0 seconds, participants were instructed to decrease the distance to the leading car until they experienced risk (risk group) or did not experience comfort anymore (comfort group). In ascending free follow sequences, starting with a time headway of 0.5 seconds, participants were instructed to increase the distance between their vehicle and the leading vehicle until they did not experience risk anymore (risk group) or experienced comfort (comfort group). Ascending and descending sequences were presented for the same three speeds as in the fixed follow conditions $(50,100,150 \mathrm{~km} / \mathrm{h})$. As in the fixed follow conditions, participants were instructed to immediately indicate when they had reached a distance where their subjective experience of the vehicle to vehicle distance changed. Each sequence lasted as long it took for the participant to reach his or her individual transition point upon which he or she informed the experimenter. The experimenter then wrote down the simulation time and stopped the scenario.

After the last free follow condition participants were informed about the background of the experiment and were given their test-subject hours. 


\section{Results}

To calculate the transition points of the fixed and free follow condition, the simulation data along with noted scenario times was used. The time headway values of the transition points were located by matching the condition time at which a participant reported a transition with the simulation data. Transition points as well as demographic data were then transferred to an SPSS 22 file. Since we cannot know where exactly a transition from, e.g., no risk to risk between the time headways of, e.g., 2.0 and 1.5 seconds in a descending large scale sequence occurred, researchers have used the mean between the two stimulus steps of a sequence as an estimated transition point, 1.75 seconds in this example (Gescheider, 1997). We therefore recalculated the transition points of the fixed follow conditions in SPSS to reflect the time headway at which a transition occurred. For large scale descending sequences, 0.25 time headway seconds were subtracted from transition points, while in large scale ascending sequences 0.25 seconds were added to the transition point. For the small scale descending sequences 0.05 seconds were subtracted, and 0.05 seconds were added for small scale ascending sequences.

Estimated transition points of the ascending and descending fixed follow sequences of the small scale are presented in Figure 3. Mean transition points of descending sequences were generally higher than the transition points of the ascending sequences.

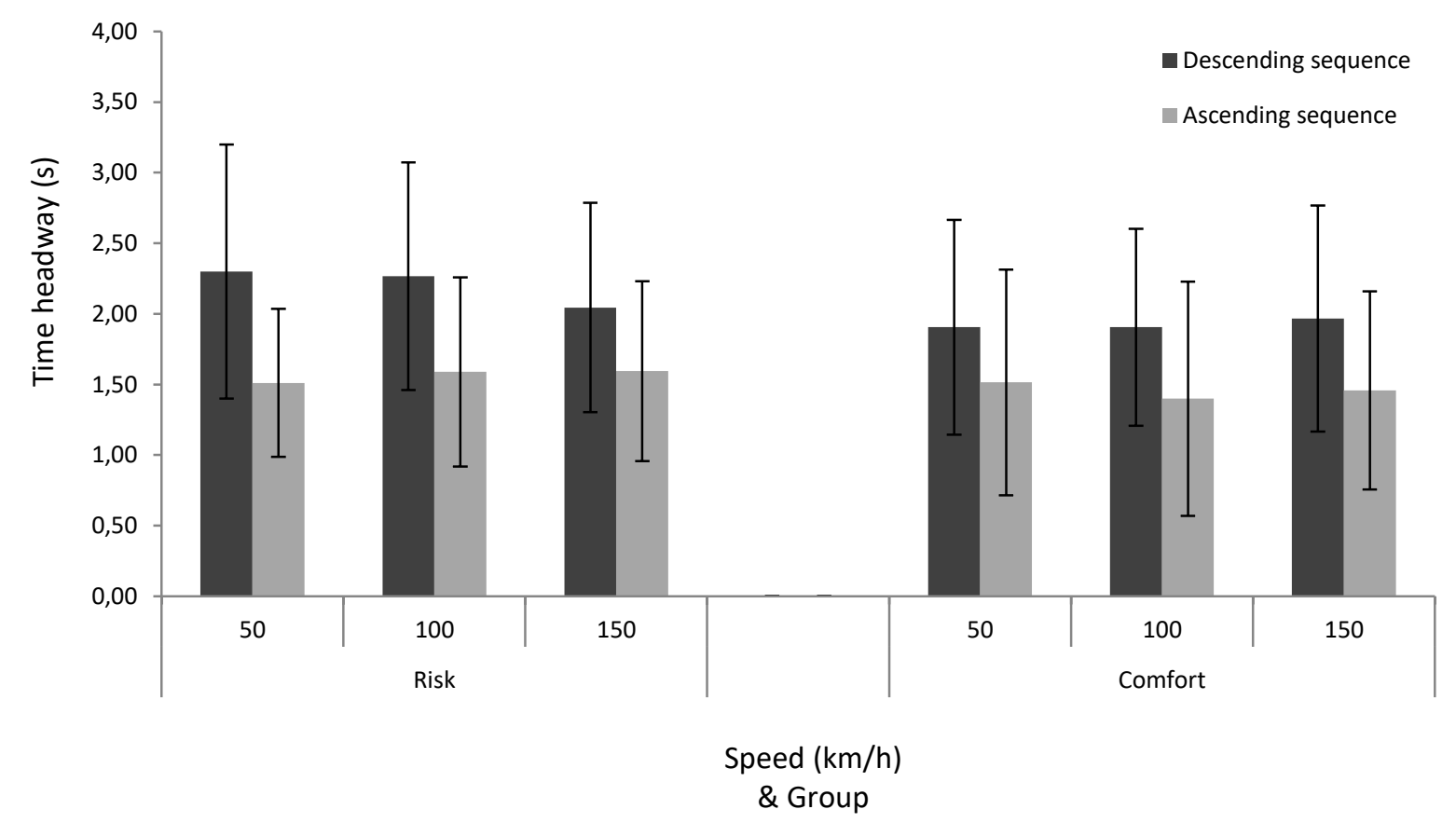

Figure 3. Mean estimated small scale transition points and standard deviations of the descending and ascending sequences. 
After the recalculation of the transition points, threshold values were calculated. The threshold values were computed as the average of the estimated transition points of an ascending and a descending sequence of the same speed and the same scale.

Mean small scale threshold values for different speeds of the risk and comfort groups are presented in Figure 4. The time headway thresholds that were calculated with the large scale sequences were very similar to the thresholds calculated using the small scale and are therefore not presented here.

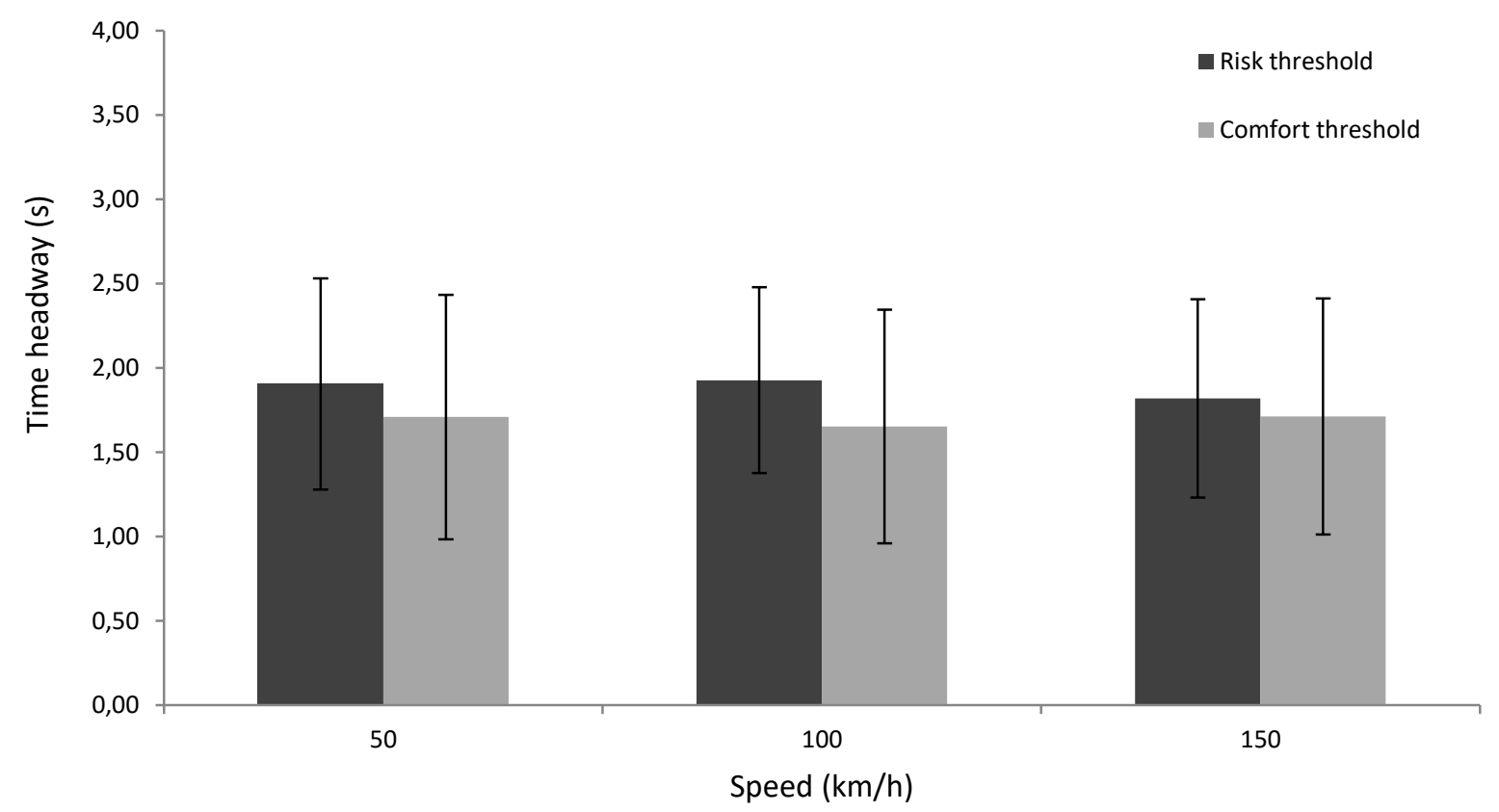

Figure 4. Mean time headway thresholds and standard deviations in the fixed follow condition of the risk and comfort group for different speed conditions calculated with the small scale sequences.

Threshold means are all located between 1.5 and 2.0 seconds (see Table 1 and Table 2).

Descriptively it appears that there is very little difference between time headway thresholds of the different speed conditions for the small scale sequences. 


\section{Table 1}

Mean time headway thresholds (in seconds) and Pearson correlations of the risk group $(n=18)$ for three different speeds and fixed and free follow conditions.

\begin{tabular}{|c|c|c|c|c|c|c|c|c|}
\hline & $M$ & $S D$ & 1 & 2 & 3 & 4 & 5 & 6 \\
\hline 1 Fixed follow risk threshold $50 \mathrm{~km} / \mathrm{h}$ & 1.91 & 0.63 & & & & & & \\
\hline 2 Fixed follow risk threshold $100 \mathrm{~km} / \mathrm{h}$ & 1.93 & 0.55 & $.85^{* *}$ & & & & & \\
\hline 3 Fixed follow risk threshold $150 \mathrm{~km} / \mathrm{h}$ & 1.82 & 0.59 & $.81^{* *}$ & $.90 * *$ & & & & \\
\hline 4 Free follow risk threshold $50 \mathrm{~km} / \mathrm{h}$ & 1.99 & 0.67 & $.76^{* *}$ & $.58 *$ & $.68 * *$ & & & \\
\hline 5 Free follow risk threshold $100 \mathrm{~km} / \mathrm{h}$ & 1.85 & 0.72 & $.78^{* *}$ & $.68^{* *}$ & $.74^{* *}$ & $.78^{* *}$ & & \\
\hline 6 Free follow risk threshold $150 \mathrm{~km} / \mathrm{h}$ & 2.00 & 0.70 & $.78 * *$ & $.68^{* *}$ & $.79 * *$ & $.73 * *$ & $.92 * *$ & \\
\hline
\end{tabular}

$* p<.05, * * p<.01$

\section{Table 2}

Mean time headway thresholds (in seconds) and Pearson correlations of the comfort group $(n=20)$ for three different speeds and fixed and free follow conditions.

\begin{tabular}{|c|c|c|c|c|c|c|c|c|}
\hline & M & SD & 1 & 2 & 3 & 4 & 5 & 6 \\
\hline 1 Fixed follow comfort threshold $50 \mathrm{~km} / \mathrm{h}$ & 1.71 & 0.73 & & & & & & \\
\hline 2 Fixed follow comfort threshold $100 \mathrm{~km} / \mathrm{h}$ & 1.65 & 0.69 & $.82 * *$ & & & & & \\
\hline 3 Fixed follow comfort threshold $150 \mathrm{~km} / \mathrm{h}$ & 1.71 & 0.70 & $.81^{* *}$ & $.79 * *$ & & & & \\
\hline 4 Free follow comfort threshold $50 \mathrm{~km} / \mathrm{h}$ & 1.88 & 0.93 & $.88^{* *}$ & $.91^{* *}$ & $.79 * *$ & & & \\
\hline 5 Free follow comfort threshold $100 \mathrm{~km} / \mathrm{h}$ & 1.98 & 1.24 & $.78^{* *}$ & $.87^{* *}$ & $.75^{* *}$ & $.94^{* *}$ & & \\
\hline 6 Free follow comfort threshold $150 \mathrm{~km} / \mathrm{h}$ & 1.80 & 0.68 & $.85^{* *}$ & $.78^{* *}$ & $.87 * *$ & $.83^{* *}$ & $.82 * *$ & \\
\hline
\end{tabular}

$* * p<.01$

The equivalent mean threshold values of the risk group expressed in meters $(\mathrm{m})$ are $26.47 \mathrm{~m}$ $(S D=8.44)$ in the $50 \mathrm{~km} / \mathrm{h}$ condition, $53.55 \mathrm{~m}(S D=14.87)$ in the $100 \mathrm{~km} / \mathrm{h}$ condition, and $75.81 \mathrm{~m}(S D=23.81)$ in the $150 \mathrm{~km} / \mathrm{h}$ condition. In the comfort group the mean threshold vehicle to vehicle distance was $23.75 \mathrm{~m}(S D=9.81)$ in the $50 \mathrm{~km} / \mathrm{h}$ condition, $45.90 \mathrm{~m}(S D=$ $18.76)$ in the $100 \mathrm{~km} / \mathrm{h}$ condition, and $71.35 \mathrm{~m}(S D=28.38)$ in the $150 \mathrm{~km} / \mathrm{h}$ condition. These meter-distance thresholds are presented in Figure 5. 


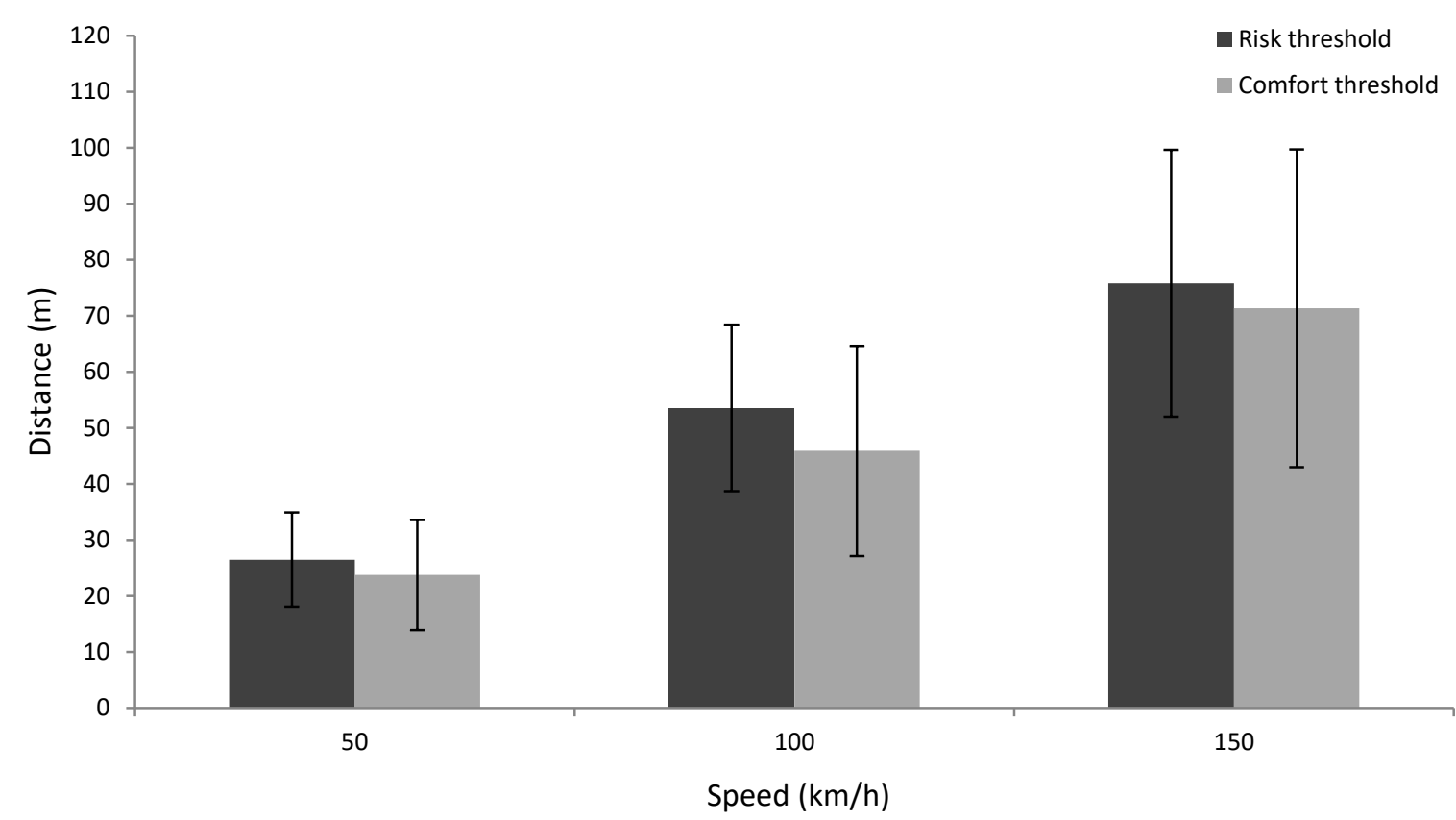

Figure 5. Mean distance thresholds in meters and standard deviations in the fixed follow condition of the risk and comfort group for different speed conditions calculated with the small scale sequences.

A Pearson correlation showed that individual time headway thresholds of the small scale sequences in the fixed follow condition correlated significantly with each other over the different speed conditions (see Table 1 and Table 2). Individual time headways for the different speeds are plotted in Figure 6 for the risk and comfort group combined. 


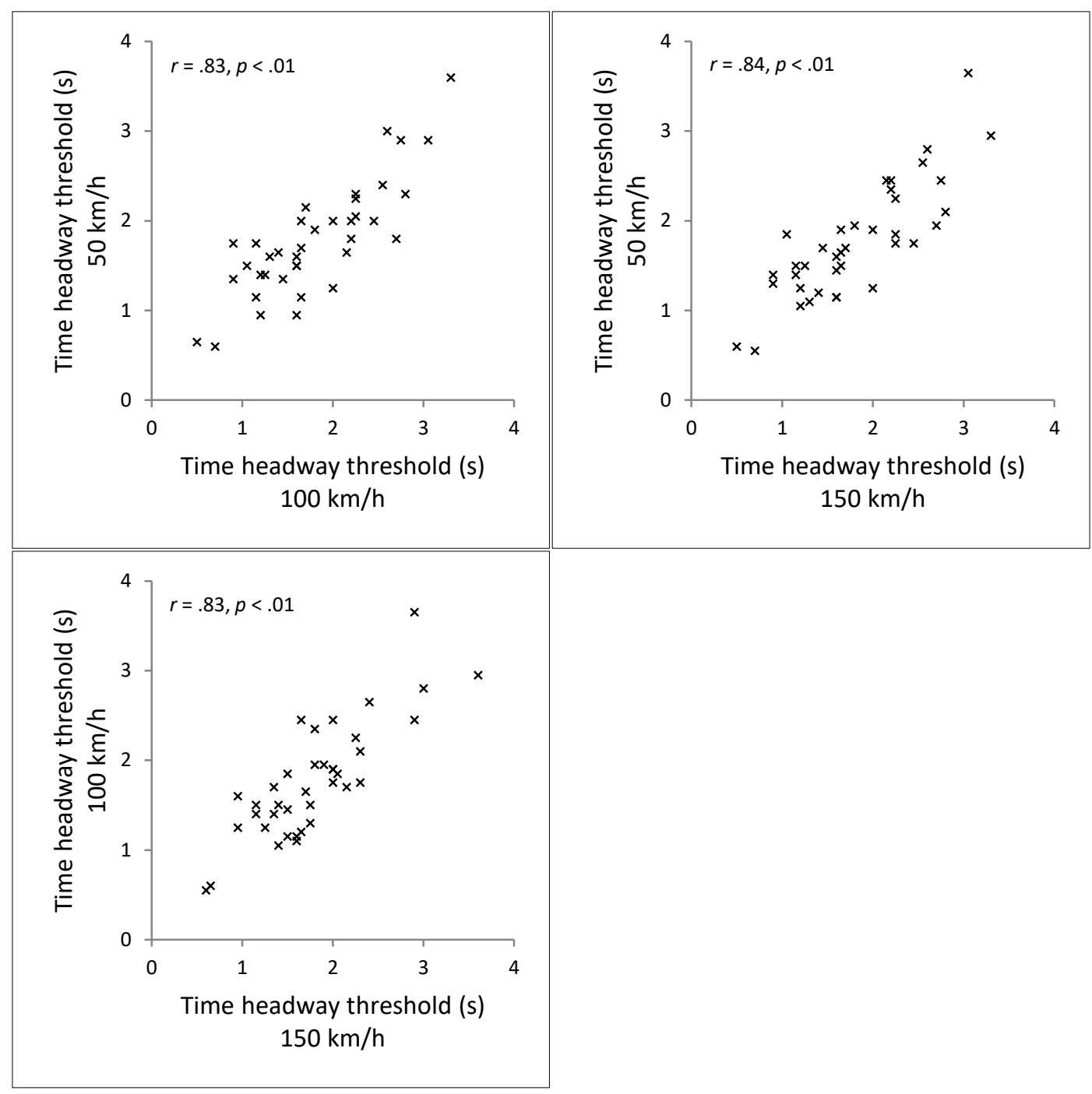

Figure 6. Individual time headway thresholds of the fixed follow condition for different speeds and the resulting correlation between them (comfort and risk group combined).

Time headway thresholds of the free follow conditions, i.e., when participants had full control of the car, are presented in Figure 7, the exact time headway values can be found in Table 1 and Table 2. Descriptively it appears that there is little influence of the speed condition on time headway thresholds in the free follow condition. 


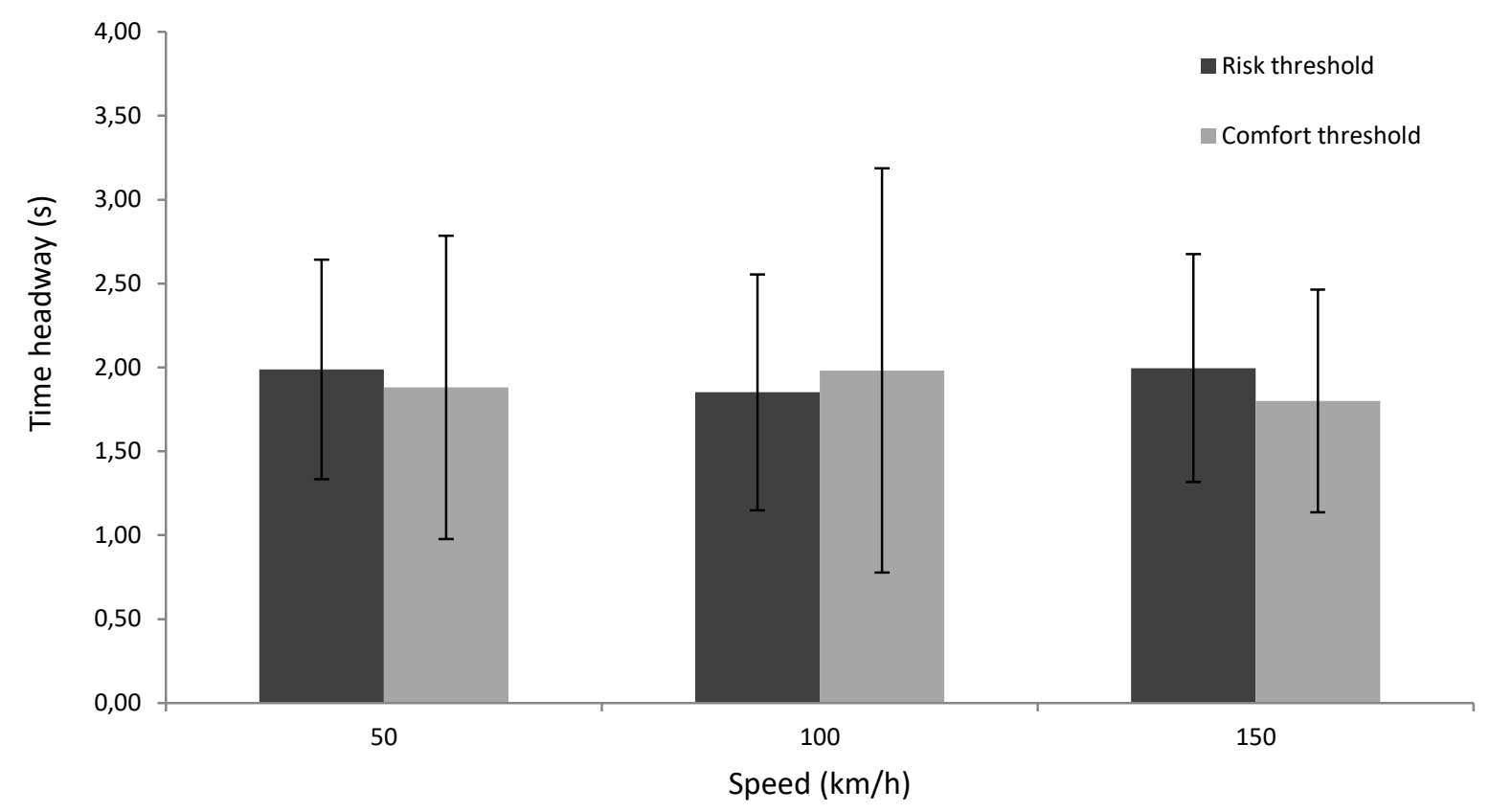

Figure 7. Mean time headway thresholds and standard deviations in the free follow condition of the risk and comfort group for different speed conditions calculated with the small scale sequences.

Calculating a Pearson's correlation for time headway thresholds for the free follow conditions shows a significant relation between time headway thresholds of different speeds (see Table 1 and Table 2).

Time headways thresholds of the free follow conditions (Figure 7) appear to be very similar to time headway thresholds observed in the fixed follow conditions (Figure 4). Fixed and free follow conditions of different speeds correlated significantly in the risk group (Table 1, $r$ $=.58$ to $.79, p<.01$ to .05 ) and in the comfort group (Table $2, r=.75$ to $.91, p<.01$ ).

To test the influence of the independent variables on time headway thresholds, a three-way $(3 \times 2 \times 2)$ repeated measures mixed analysis of variance (ANOVA) was performed, with the factors speed (within-subjects; $50 \mathrm{~km} / \mathrm{h}, 100 \mathrm{~km} / \mathrm{h}, 150 \mathrm{~km} / \mathrm{h}$ ), group (between-subjects; risk group vs. comfort group), and follow condition (within-subjects; free vs. fixed). There was no significant main effect for speed, i.e., there is no significant influence of speed on the time headway thresholds of participants $\left(F_{(2,72)}=0.21, p=.81, \eta_{p}{ }^{2}=0.01\right)$. There was also no main effect for the group participants were in, i.e., there is no significant difference in time headway thresholds between the risk and the comfort group $\left(F_{(1,36)}=0.32, p=.58, \eta_{p}{ }^{2}=\right.$ 0.01). The influence of the follow condition, i.e., the comparison of time headway thresholds of the fixed and free follow condition did just fail to be significant $\left(F_{(1,36)}=4.10, p=.05, \eta_{p}^{2}\right.$ $=0.10)$. 


\section{Discussion}

In this study we investigated the thresholds for subjective risk and comfort experience in car following. We used a refined version of the method of limits to determine time headway thresholds similar to the studies by Gouy et al. $(2012,2013)$. Time headway was presented in ascending and descending sequences to locate participants' individual risk respectively comfort thresholds for different speeds. Self-reported risk and self-reported comfort were assessed in a between-subject design to avoid response biases. Before conducting the experiment, we proposed hypotheses about the location of time headway thresholds in general, of individual thresholds, thresholds over different speeds, and between the risk and comfort group.

Our first hypothesis stated that mean time headway thresholds for the experience of risk and comfort would be located between 1.5 and 2.0 seconds. Our results (Figure $4 \&$ Figure 7) add to the growing evidence of a mean threshold for subjective experience between 1.5 and 2.0 time headway seconds in simulated driving (Lewis-Evans et al., 2010; Siebert et al., 2014). Since absolute validity was not assessed for our simulator, these results are not directly transferable to real-life driving.

In our second hypothesis we assumed that there would be no significant difference in time headway thresholds over the different speed conditions, i.e., that speed has no significant influence on time headway thresholds. Figure 5 shows participants' thresholds as the meter distance, and it can be seen that meter-wise, the thresholds for different speeds are very different. When transferred to time headway thresholds (Figure 4) this difference disappears. A repeated measures mixed ANOVA did not show a significant difference between time headway thresholds of different speed conditions. This result indicates a general validity of time headway as a variable in car following. Participants were not aware that the distance sequences that were displayed in the experiment were varied in 0.5 respectively 0.1 seconds time headway increments. Still, our results show that participants experience and rate distances in car following by their equivalent time headway value.

With our third hypothesis we assumed that individual time headway thresholds would correlate positively and significantly over different speeds, e.g., that a participant with a relatively low threshold in the $50 \mathrm{~km} / \mathrm{h}$ condition would also have a relatively low threshold in the 100 and $150 \mathrm{~km} / \mathrm{h}$ condition. We found that individual thresholds correlate significantly with each other over different speed conditions (Figure 6). 
In our fourth hypothesis we expected time headway thresholds in the comfort group to be higher than in the risk group. We found that there is no significant difference between thresholds of the risk and comfort group. Furthermore, Figure 4 shows that, while not significant, mean thresholds are actually higher in the risk group than in the comfort group. This could be interpreted as there still being a feeling of comfort present for time headway distances at which an experience of risk is reported. Why is that? Our assumption of higher comfort thresholds was based on the idea that a driver would lose his feeling of comfort before he or she would experience risk. While the results of our study do not support this assumption, the results might be influenced by a flaw in our study design. As explained earlier, participants were presented with ascending and descending sequences of time headways. While the presentation of sequences was randomized, there might be a cognitive difference in monitoring risk and comfort in participants. The variables used are different in that risk is a negative experience, while comfort is a positive experience. In a descending sequence a participant in the risk group is anticipating an emerging feeling of risk, while a participant in the comfort group is anticipating the disappearance of comfort. This contrast is switched for ascending time headway sequences and should therefore, theoretically level out. As the mean transition points of ascending and descending series plotted in Figure 3 show, this effect is more pronounced in the descending sequences, leading to the observed effect of higher thresholds in the risk group compared to the comfort group. Due to this effect, the question about a possible underlying variable posed by Lewis-Evans et al. (2010) has to be left unanswered.

In our fifth hypothesis we assumed that individual time headways of the free and the fixed follow condition would correlate positively and significantly. While individual time headways of the free and fixed follow conditions correlate significantly, a comparison of the fixed and free follow condition just failed to show a significant difference between the two groups. This is an indication that participants prefer for example small time headways in both the fixed and free follow condition, but that thresholds still differ between the fixed and free follow condition. For the development of level 3 automation in vehicles, our results suggest that selfdriving thresholds can give an indication for thresholds in automated driving. However, it is important to keep in mind that distance thresholds in ACC have been shown to be influenced by the amount of system use (Pereira, Beggiato, \& Petzoldt, 2015) and we did not control for prior ACC use in our study.

Overall our results suggest that level 1,2, and 3 automation vehicles need to adapt to the individual driver's time headway threshold. While the results for our first hypothesis show 
that the mean time headway threshold lies between 1.5 and 2.0 seconds, individual thresholds can be found outside of this range (Figure 6). Individual thresholds of the free follow conditions, i.e. level 0 automation, correlate significantly with thresholds of the fixed follow conditions, i.e. level 1 automation. Since individual thresholds in our study are also consistent over a broad range of speeds, it is in theory possible to extrapolate from an individual selfdriving threshold at a single speed to individual thresholds for level 1 automation driving at different speeds.

There are several limitations to this study. While there is evidence for a general comparability of preferred time headways of real world and simulated driving, we did not test the absolute and relative validity of our specific driving simulator setup. Our results for time headway thresholds can therefore be influenced by differences between simulated and real-life driving, such as the lack of real crash risk in a driving simulator (Risto \& Martens, 2014) and differences in criticality ratings of time headways in simulated and real-life driving (Purucker et al., 2014). The effect of underestimated criticality in simulated driving might explain the comparatively large time headways found in this study, compared to the relatively small time headways found in real-life driving (Brackstone, Sultan, \& McDonald, 2002, Brackstone, Waterson, \& McDonald, 2009). Nevertheless, we argue that while the precise time headway threshold value might change for real life driving (absolute validity), it would still be constant over different speeds (relative validity). Another limitation of this study is the lack of speed differences between the lead and the following car. In real life driving, drivers need to constantly accelerate and decelerate when following another vehicle, leading to complex speed adjustment patterns (Brackstone, Sultan, \& McDonald, 2002). Since the speed of the participants' vehicle and the lead vehicle was fixed, these patterns were not present in our study. Furthermore, the surrounding traffic in our study adheres to a minimum following distance of two seconds, which is higher than individual time headways found in our study and in real life driving (Knospe, Santen, Schadschneider, \& Schreckenberg, 2002).

As discussed earlier, self-reported risk and self-reported comfort do not necessarily equate the subjective experience of risk and the subjective experience of comfort. Reported risk and reported comfort thresholds from the fixed follow conditions do not differ significantly from the experienced thresholds of the free follow conditions in which participants had complete control over the car. This could be interpreted as an indication for the validity of using selfreported experiences in lieu of more directly measuring subjective experience. This comparison just failed to show a significant difference, so more research into this is needed. 
For future studies it seems advisable to balance the order of free follow and fixed follow conditions so a possible effect of sequence can be controlled. Our two stage utilization of the method of limits proved to be an efficient method to identify participants' thresholds. Presenting all time headway thresholds between 0.5 and 4.0 seconds with a resolution of 0.1 seconds would have resulted in 36 experimental conditions. With our two stage approach participants were on average presented with only 18.35 conditions before a threshold was found. Our advanced method therefore allows researching a broader time headway range compared to the study by Gouy et al. $(2012,2013)$ without increasing the number of experimental conditions. Results show that it is important to consider possible effects of the chosen variable for threshold detection, as the valence of the variable appears to influence ascending and descending sequences differently.

For future application of the two stage method of limits, as well as the classic method of limits it is important to vary the starting points of each ascending and descending sequence. In this study we used fixed starting points for the time headway sequences, 0.5 and 4.0 seconds, to research the same time headway range as in preceding articles (Lewis-Evans et al., 2010; Siebert et al., 2014). In hindsight it seems advisable to vary time headway sequence starting points, since starting a sequence out of the researched range can help to mitigate possible errors of expectation (Gescheider, 1997). The only downside of this variation is a small increase in the number of conditions presented, deviating from the 0.5 second increments (4.0, 3.5, $3.0 \ldots$...) in presented headways should not influence headway thresholds.

Further improvement to the two stage approach might be possible by using a mix of psychophysical methods. The two stage method of limits provides two transition point reports from each participant, one for the small scale descending, and one for the small scale ascending sequence. To increase the number of transition points, it would be possible to first use the method of limits large scale sequences, to determine a first estimate of an individual's transition point, and to then use the so called staircase method with smaller increments, in which the direction of the stimulus sequence is switched when a transition is reported. This would increase the number of transition points and would in theory provide a more exact transition point estimate. Gescheider (1997, p.50-51) provides a more thorough explanation of this method.

The results of this study for the programming of autonomous cars lie in the stability of time headways for different speeds. While participants show inter-individual differences in time headway thresholds, intra-individual time headway thresholds are constant over a range of 
speeds. Further research on the influence of external factors on time headway thresholds, such as weather, traffic, and type of vehicle that is followed is needed to form a coherent model for time headway thresholds in autonomous driving. The influence of personality traits on individual time headway thresholds was also not controlled for in this study. Research has shown that following behavior can be influenced by individual factors in self-driving (Heino, van der Molen, \& Wilde, 1996; Ohta, 1993), this could also influence time headway thresholds in automated driving. Since there are no differences in velocity between the lead and the participant's vehicle in this study, the influence of differences in velocity between two vehicles and the resulting occurrence of non-zero time to collision should be researched. Frequent usage of adaptive cruise control can over time have an influence on time headway distance thresholds (Pereira et al. 2015), and just observing other cars driving with relative short time headways, in so called platoons, also temporarily influences preferred time headway distances in drivers (Gouy et al., 2014). Driving automated in platoons furthermore changes a driver's time headway in the subsequent self-driving (Skottke, Debus, Wang, \& Huestegge, 2014). These findings and their possible interaction with time headway thresholds at different speeds need to be researched in more detail.

\section{References}

Ayres, T. J., Li, L., Schleuning, D., \& Young, D. (2001). Preferred time-headway of highway drivers. In Intelligent Transportation Systems, 2001. Proceedings. 2001 IEEE (pp. 826-829). IEEE.

Bella, F. (2008). Driving simulator for speed research on two-lane rural roads. Accident Analysis \& Prevention, 40(3), 1078-1087.

Brackstone, M., Sultan, B., \& McDonald, M. (2002). Motorway driver behaviour: studies on car following. Transportation Research Part F: Traffic Psychology and Behaviour, 5(1), 31-46.

Brackstone, M., Waterson, B., \& McDonald, M. (2009). Determinants of following headway in congested traffic. Transportation Research Part F: Traffic Psychology and Behaviour, 12(2), 131-142.

Brecher, G. A. (1934). Die untere Hör-und Tongrenze. Pflüger's Archiv für die gesamte Physiologie des Menschen und der Tiere, 234(1), 380-393.

Carsten, O., \& Jamson, A. H. (2011). Driving simulators as research tools in traffic psychology. Handbook of traffic psychology, 87-96.

Fechner, G. T. (1860). Elemente der psychophysik. Leipzig: Breitkopf und Härtel.

Fletcher, H., \& Wegel, R. L. (1922). The Frequency—Sensitivity of Normal Ears. Physical review, 19(6), 553.

Fuller, R. (2005). Towards a general theory of driver behaviour. Accident Analysis \& Prevention, 37(3), 461-472. 
Gescheider, G. A. (1997). Psychophysics: The Fundamentals (3rd ed.). Mahwah, N.J.: L. Erlbaum Associates. Godley, S. T., Triggs, T. J., \& Fildes, B. N. (2002). Driving simulator validation for speed research. Accident analysis \& prevention, 34(5), 589-600.

Gouy, M., Diels, C., Reed, N., Stevens, A., \& Burnett, G. (2012). Preferred time headway assessment with the method of limits. In J.-F. P. P. V. Mora, \& L. Mendoza (Eds.), European Conference on Human Centered Design for Intelligent Transport Systems: 87-93.

Gouy, M., Diels, C., Reed, N., Stevens, A., \& Burnett, G. (2013). Preferred or adopted time headway? A driving simulator study. In Proceedings of the International Conference on Ergonomnics \& Human Factors, M. Anderson, Ed (pp. 153-159).

Gouy, M., Wiedemann, K., Stevens, A., Brunett, G., \& Reed, N. (2014). Driving next to automated vehicle platoons: How do short time headways influence non-platoon drivers' longitudinal control?. Transportation research part F: traffic psychology and behaviour, 27, 264-273.

Heino, A., van der Molen, H. H., \& Wilde, G. J. (1996). Differences in risk experience between sensation avoiders and sensation seekers. Personality and individual differences, 20(1), 71-79.

Kemeny, A., \& Panerai, F. (2003). Evaluating perception in driving simulation experiments. Trends in cognitive sciences, 7(1), 31-37.

Knospe, W., Santen, L., Schadschneider, A., \& Schreckenberg, M. (2002). Single-vehicle data of highway traffic: Microscopic description of traffic phases. Physical Review E, 65(5).

Lewis-Evans, B., De Waard, D., \& Brookhuis, K. A. (2010). That's close enough-A threshold effect of time headway on the experience of risk, task difficulty, effort, and comfort. Accident Analysis \& Prevention, 42(6), 1926-1933.

Marsden, G., McDonald, M., \& Brackstone, M. (2001). Towards an understanding of adaptive cruise control. Transportation Research Part C: Emerging Technologies, 9(1), 33-51.

Muir, B. M. (1994). Trust in automation: Part I. Theoretical issues in the study of trust and human intervention in automated systems. Ergonomics, 37(11), 1905-1922.

Näätänen, R., \& Summala, H. (1974). A model for the role of motivational factors in drivers' decisionmaking. Accident Analysis \& Prevention, 6(3), 243-261.

NHTSA (2013). US Department of Transportation Policy on Automated Vehicle Development, p4. See http://www.nhtsa.gov/About+NHTSA/Press+Releases/U.S.+Department+of+Transportation+Releases+Policy+o o+Automated+Vehicle+Development

Ohta, H. (1993). Individual differences in driving distance headway. Vision in vehicles, 4, 91-100.

Parasuraman, R., \& Riley, V. (1997). Humans and automation: Use, misuse, disuse, abuse. Human Factors: The Journal of the Human Factors and Ergonomics Society, 39(2), 230-253.

Pereira, M., Beggiato, M., \& Petzoldt, T. (2015). Use of adaptive cruise control functions on motorways and urban roads: Changes over time in an on-road study. Applied Ergonomics, 50, 105-112. 
Purucker, C., Rüger, F., Schneider, N., Neukum, A., \& Färber, B. (2014, July). Comparing the perception of critical longitudinal distances between dynamic driving simulation, test track and Vehicle in the Loop. In Advances in human aspects of transportation. Proceedings of the 5th AHFE Conference. Krakau, Polen (Vol. 19, No. 23.07, pp. 421-430).

Risto, M., \& Martens, M. H. (2014). Driver headway choice: A comparison between driving simulator and realroad driving. Transportation research part F: traffic psychology and behaviour, 25, 1-9.

Siebert, F. W., Oehl, M., \& Pfister, H. R. (2014). The influence of time headway on subjective driver states in adaptive cruise control. Transportation research part F: traffic psychology and behaviour, 25, 65-73.

Skottke, E. M., Debus, G., Wang, L., \& Huestegge, L. (2014). Carryover effects of highly automated convoy driving on subsequent manual driving performance. Human Factors: The Journal of the Human Factors and Ergonomics Society, 56(7), 1272-1283.

Stanton, N. A., \& Young, M. S. (2005). Driver behaviour with adaptive cruise control. Ergonomics, 48(10), 1294-1313.

Summala, H. (1988). Risk control is not risk adjustment: The zero-risk theory of driver behaviour and its implications. Ergonomics, 31(4), 491-506.

Taieb-Maimon, M., \& Shinar, D. (2001). Minimum and comfortable driving headways: Reality versus perception. Human Factors: The Journal of the Human Factors and Ergonomics Society, 43(1), 159-172.

Taylor, D. H. (1964). Drivers' galvanic skin response and the risk of accident. Ergonomics, 7(4), 439-451.

Winsum, W. V., \& Heino, A. (1996). Choice of time-headway in car-following and the role of time-to-collision information in braking. Ergonomics, 39(4), 579-592.

Yan, X., Abdel-Aty, M., Radwan, E., Wang, X., \& Chilakapati, P. (2008). Validating a driving simulator using surrogate safety measures. Accident Analysis \& Prevention, 40(1), 274-288. 